\title{
Integrated Rice-Duck Farming Decreases Soil Seed Bank and Weed Density in a Paddy Field
}

\author{
Hui Wei ${ }^{1,2,3,4}$, Wenjuan Bai ${ }^{1}$, Jiaen Zhang ${ }^{1,2,3,4, *}$, Rui Chen ${ }^{1}$, Huimin Xiang ${ }^{1,2,3,4}$ and \\ Guoming Quan ${ }^{3,5}$ \\ 1 Department of Ecology, College of Natural Resources and Environment, South China Agricultural \\ University, Guangzhou 510642, China; weihui@scau.edu.cn (H.W.); bwjlucky@163.com (W.B.); \\ ronadle@126.com (R.C.); rabbitxhm@163.com (H.X.) \\ 2 Key Laboratory of Agro-Environment in the Tropics, Ministry of Agriculture, Guangzhou 510642, China \\ 3 Guangdong Engineering Research Center for Modern Eco-agriculture and Circular Agriculture, \\ Guangzhou 510642, China; gzbyqgm@126.com \\ 4 Guangdong Provincial Key Laboratory of Eco-Circular Agriculture, Guangzhou 510642, China \\ 5 Department of Urban Construction Engineering, Guangzhou City Polytechnic, Guangzhou 510405, China \\ * Correspondence: jeanzh@scau.edu.cn; Tel.: + 86-208-528-0211
}

Received: 30 April 2019; Accepted: 20 May 2019; Published: 22 May 2019

\begin{abstract}
Coupled cropping-breeding modes have been highly recommended due to their ecological and sustainable nature. Integrated rice-duck farming is a typical ecological planting system in rice paddy fields and has been widely popularized in Asia where a considerable area of cropland has been planting rice. In this study, two experimental treatments of turbid water or rice-duck treatment were established to compare with the control and a conventional treatment in absence of ducks. The turbid water treatment imitated the muddying effect by duck activities with the trampling and foraging effects excluded, while the rice-duck treatment included all of the mentioned effects by raising ducks in rice paddy field. Results showed that the rice-duck treatment significantly reduced soil seed bank density by more than $40 \%$ and the figures under the turbid water treatment were $18.2 \%$ and $30.5 \%$, accordingly, in the early and late rice growing seasons. Moreover, the rice-duck treatment significantly altered the vertical distribution of soil seed bank by substantially declining the seed density in the topsoil $(0-5 \mathrm{~cm})$. Changes in soil seed bank density considerably contributed to the declines in above-ground weed density because a significant correlation was detected between the soil seed bank density in the early season and the weed density in the late season. Our results of declined soil seed bank and weed density in integrated rice-duck farming imply that this system is highly efficient as a biological pathway for controlling weeds.
\end{abstract}

Keywords: integrated farming system; sustainable agricultural practice; soil seed bank; weed control; rice paddy field

\section{Introduction}

Rapid growing yield of crops by industrial agriculture associated with intensive application of agrochemicals has succeeded to feed the increasing population worldwide [1]. Intensified use of agrochemicals and fertilizers may have caused environmental pollution [2-4], which potentially threats food safety by decreasing availability of arable land and resources such as clean soil, water, and foods free of contaminations [5,6]. Integrated rice-duck farming is a popular plant-raising system due to its economic, environmental, and ecological benefits reported previously [7]. In spite of negative effects potentially related to breeding ducks in rice fields [8,9], positive effects have been noted in previous literature. Typically, raising ducks could be beneficial to control weeds and their seed density 
in soils, to decrease possibility of pest outbreak, and to increase rice yield and quality by promoting soil fertility [10-12]. Consequently, integrated rice-duck farming can maintain rice productivity at a comparable or greater level than conventional farming, which involves high cost investments due to needs of labor and agrochemicals. By contrast, integrated rice-duck farming may enable reduced use of agrochemicals to improve environment of croplands and quality of crops $[8,10,13]$. Rice-duck farming may also be able to mitigate global warming potential by remarkably reducing soil $\mathrm{CH}_{4}$ emission [14-16]. This reduction could be associated with the combination of reductions in soil $\mathrm{CH}_{4}$ production, but increases in $\mathrm{CH}_{4}$ oxidation, because the movements of ducks could greatly change growth of rice plants and field environments, such as substrate supplies, soil aerobic condition, and dissolved oxygen concentration in water [14-16]. Moreover, growing ducks in paddy fields could decrease potential risk from damages of invasive species to rice plants, such as golden apple snail Pomacea canaliculata Lamarck $[8,17]$. Therefore, the integrated rice-duck farming has been widely accepted as a sustainable agroecological system around the world $[8,10,18]$.

In rice-duck farming system, rice can grow healthily and rapidly without applications of chemical fertilizers, pesticides, and herbicides due to stimulating effect from constant duck movement in crop fields [19-21]. Duck activities, like walking and predation, had significant impacts on weed community structure and weeds could thus be efficiently controlled in the rice-duck fields [22,23]. Previous studies concluded that there was significantly fewer abundance of weed species and a high percentage of weeds could be eliminated in the rice field with ducks raising [24]. Efficiency of weed control by rearing ducks in the rice fields was ever reported to be higher compared with applying herbicides [25,26], implying high weed-control efficiency of the integrated farming mode. Furthermore, duck activities could effectively inhibit not only common weeds, but also some weeds that were not well controlled by herbicides, such as Paspalum distichum L., Eclipta prostrata (L.) L., Marsilea quadrifolia L., Monochoria vaginalis (N. L. Burman) C. Presl ex Kunth, and Echinochloa crusgalli (L.) P. Beauv. [25,26], indicating the rice-duck farming being environmentally friendly.

Although mentioned studies have grasped the symptom that raising ducks could notably control weeds in rice paddy fields, the mechanisms regarding how duck activities control weed infestation remain unclear. The weed control pattern by raising ducks is probably attributed to three potential mechanisms that are trampling and foraging by duck activities, muddying effect, and duck-induced microclimatic changes in rice land, as proposed in previous studies $[8,13,27]$. Therein, the first one, i.e., trampling and foraging of ducks, could contribute the most proportion for weed control in the rice-duck system [13]. In arable fields, the vast majority of weed species are annuals and seeds that are mainly stored in the soil as soil seed bank is the major source for the renewal of weed populations [28,29]. Therefore, soil seed bank plays an important role in the composition of the weed communities and thus in their control. Previous studies showed that consecutive rice-duck farming tremendously declined the density of weeds and soil seed bank in croplands [24,30]. However, empirical experiments remain in demand to observe the effects of raising ducks on the soil seed bank of rice paddy fields, e.g., the seed density and its vertical distribution.

The present study was conducted to clarify how duck activities affected soil seed bank and weed density in a long-term rice paddy field of southern China, one of the main rice-producing regions in China [31]. Soil seed bank at three soil depths $(0-5 \mathrm{~cm}, 5-10 \mathrm{~cm}$, and 10-15 cm) and weed density were investigated at the end of the early and late seasons of rice growth, respectively. We expected that raising ducks could significantly decline the soil seed bank density relative to the control, based on the existing knowledge as reported in previous literature [24,30]. These previous studies reported a decline in soil seed bank density due to raising ducks in the rice fields, although they did not separate effects of raising ducks in the rice fields as we did, e.g., to investigate muddy effects due to movements of ducks. Furthermore, the vertical distribution of seeds in the soil was expected to be altered by duck trampling and foraging that could occur mostly at the first surface soil layer. Moreover, we also aimed to test the potential correlation between soil seed density and weed density and provide empirical 
evidences to support the explanation that raising ducks in rice paddy fields controlled weeds by means of declining soil seed bank density.

\section{Materials and Methods}

\subsection{Site Descriptions}

The experiment was conducted in Zengcheng Teaching and Research Farm $\left(23^{\circ} 14^{\prime} \mathrm{N}, 113^{\circ} 38^{\prime} \mathrm{E}\right)$ of South China Agricultural University. The study site has a subtropical climate, with the annual temperature of $22^{\circ} \mathrm{C}$ and the annual rainfall of $1800-1900 \mathrm{~mm}$. The most (around $80 \%$ ) of precipitation occurs in the wet season that ranges from April to September, and the remaining months of a calendar year are generally regarded as the dry season. The paddy field soil in the farm is developed from Latosol and has a $\mathrm{pH}$ of 6.0 with $108.0 \mathrm{mg} \mathrm{kg}^{-1}$ extractable nitrogen, $27.59 \mathrm{mg} \mathrm{kg}^{-1} \mathrm{HCl}-\mathrm{NH}_{4} \mathrm{~F}$-extractable phosphorus, $0.54 \mathrm{~g} \mathrm{~kg}^{-1}$ total phosphorus, $18.27 \mathrm{~g} \mathrm{~kg}^{-1}$ total nitrogen, and $33.02 \mathrm{~g} \mathrm{~kg}^{-1}$ organic matter. Rice of two seasons (early and late seasons) were cultivated to investigate treatment effects in this study, because the study site belongs to the double cropping area of southern China where two seasons of rice can be cultivated in one calendar year. Climatic condition including air temperature and precipitation is presented in Figure 1.

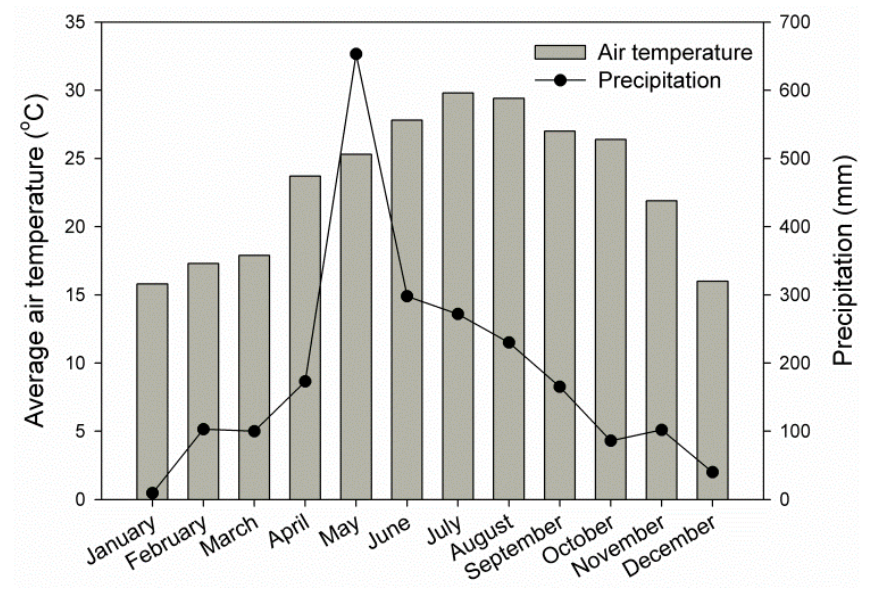

Figure 1. Monthly average air temperature and the amount of precipitation in the investigation year [32].

\subsection{Experimental Design}

The rice (Oryza sativa L.) variety used in this study was Sheng Ba Si Miao, provided by South China Agricultural University, and the ducks were a domestic Mallard (Anas platyrhynchos domesticus). The used farmland receives convenient irrigation and drainage and has homogeneous soil fertility level in prior to the experiment. Experimental plots with the size of $133 \mathrm{~m}^{2}$ were established in year 2006 to set up four treatments in the present study, with ridges (height of $30 \mathrm{~cm}$ and width of $80 \mathrm{~cm}$ ) built between each two plots, and each treatment had three replicates. The four treatments included a control in the absence of duck activities and any chemicals, a conventional planting treatment with fertilizers, pesticides and herbicides applied, a turbid water treatment by duck activities around the plots but not allowed in the plots, and a rice-duck farming treatment with ducks in the plots. In the experimental plots with duck activities, five ducklings (5-10 days old) were released in each plot, which made the duck density approximating to 375 ducks per hectare as recommended by Zhang et al. [13]. Besides chemicals applied in the conventional planting plots, the same field managements were conducted in all the experimental plots.

To ensure muddying effect in the turbid water treatment, $2 \times 2 \mathrm{~m}^{2}$ enclosed spaces were further fenced by nylon net in the plots. Therefore, water could go through freely, but without ducks allowed in. This treatment made a muddying effect but foraging and trampling of ducks were prevented from 
entering the enclosed spaces, whereas the rice-duck farming treatment received both of the muddy and foraging and trampling effects by duck activities. In the rice-duck farming plots, five ducks were released into each plot after rice transplanting and were driven out of the plots until the rice heading stage. The plots receiving the rice-duck farming treatment were separated by nylon-net to prevent ducks from escaping and being harmed by enemies. The turbid water treatment was conducted as shown below in Figure 2.
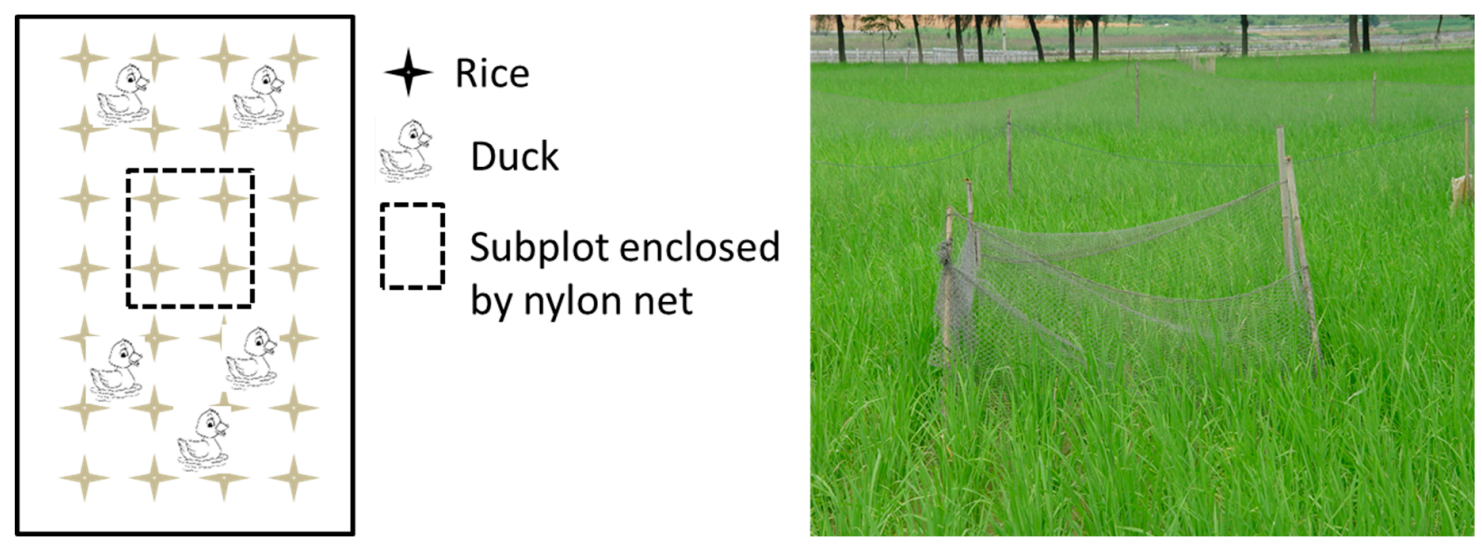

Figure 2. The scheme and a photo of turbid water treatment conducted in this study. Ducks could not move into the subplot enclosed by nylon net to trample and forage, but the muddying water could exchange in and out of the subplot due to the movements of ducks around the subplot.

\subsection{Seed Identification and Field Weed Investigation}

The soils were sampled at the end of early and late seasons of rice growth after ducks were driven out of the plots. Finally, duration of the rice-duck treatment in the early and late seasons was 63 and 53 days, respectively. Ten soil cores were collected at random from three depths $(0-5 \mathrm{~cm}, 5-10 \mathrm{~cm}$, and $10-15 \mathrm{~cm}$ ) in each plot, using a cylinder with the diameter of $10 \mathrm{~cm}$. The 10 cores of samples at each soil depth were mixed as one composite sample for the further analyses.

Germination method was used to investigate viable soil seed bank density because this method could precisely enumerate the readily germinable seeds [29]. Each soil sample was thoroughly mixed and spread evenly in a $410 \mathrm{~cm} \times 265 \mathrm{~cm} \times 75 \mathrm{~cm}$ germination containers to form an approximately $3 \mathrm{~cm}$ soil layer for germination. The containers were kept humid by spraying water daily using a handheld sprayer. Seedlings that emerged from soil samples were identified according to Illustrated handbook of farmland weeds in China [33] and counted. Those seedlings were removed as soon as they were identified to avoid overcounting and some space was provided for the remaining seeds. Those seedlings that could not be easily identified were transplanted to pots and grown until identified. When only few seeds germinated, the soil in each container was dried, mixed, and rewetted and fertilizers (Batian compound fertilizer with the ratio of nitrogen, phosphorus and potassium being 15:5:25, Batian Ecological Engineering Co. Ltd., Shenzhen, China) were applied at the dose of approximately $180 \mathrm{~kg}$ per hectare to ensure maximum germination for seed identification.

Field weed investigation was finished in prior to soil samplings at the end of early and late seasons of rice growth. In each experimental plot, five $1 \times 1 \mathrm{~m}^{2}$ subplots were at random selected to record the number of weed and then average weed density was calculated in individuals per square meter to indicate weed density.

\subsection{Statistical Analysis}

The number of seeds germinated from all the soil samples was recorded as individual $\mathrm{m}^{-2}$. Statistical analyses were performed using IBM SPSS Statistics version 22.0 (IBM Corp., New York, NY, US). Assumptions of normality and homoscedasticity were tested, and data were logarithmically 
transformed given that the assumptions were not met. One-way analysis of variance (ANOVA) was used to detect the significant differences among treatments or soil depths. Differences among means were assessed using Duncan' range test at a level of $p<0.05$. Linear regression was conducted to test the significance of linear relationships between seed density and soil weed bank density. All the figures were made in SigmaPlot 10.0 (Systat Software Inc., San Jose, CA, US).

\section{Results}

\subsection{Effects on Composition and Density of Soil Seed Bank}

Soil seed bank included a total of 11 species that belongs to seven families at the end of the early season of rice growth (Table 1). The number of species was 10,11,10, and nine in the control, conventional planting, turbid water treatment, and rice-duck farming plots, respectively. Four dominant species, i.e., Cyperus difformis L., Fimbristylis miliacea (L.) Vahl, Lindernia procumbens (Krock.) Philcox, and Rotala indica (Willd.) Koehne, accounted for $89.9 \%, 91.0 \%, 93.2 \%$, and $89.2 \%$ of the total soil seed bank in the control, conventional planting, turbid water treatment, and rice-duck farming plots, respectively. At the end of the late season, in total, nine species in six families were detected in soil seed bank, with the number of species being nine in the control, conventional planting, and turbid water treatment plots, and eight in the rice-duck farming plots (Table 2). The first four species were Alopecurus japonicus Steud., C. difformis, L. procumbens, and E. crusgalli that contributed in total 91.9\%, $91.9 \%, 91.7 \%$, and $91.1 \%$ to soil seed bank composition in the control, conventional planting, turbid water treatment and rice-duck farming plots, respectively.

Table 1. Soil seed bank composition (individuals $\mathrm{m}^{-2}$ ) under different treatments in the early season of rice growth.

\begin{tabular}{ccccc}
\hline Species & Control & $\begin{array}{c}\text { Conventional } \\
\text { Planting }\end{array}$ & $\begin{array}{c}\text { Turbid Water } \\
\text { Treatment }\end{array}$ & $\begin{array}{c}\text { Rice-Duck } \\
\text { System }\end{array}$ \\
\hline $\begin{array}{c}\text { Gramineae } \\
\text { Echinochloa crusgalli (L.) P. Beauv. }\end{array}$ & $12 \pm 12$ & $18 \pm 11$ & 0 & 0 \\
$\begin{array}{c}\text { Echinochloa crusgalli var. mitis } \\
\text { Leptochloa chinensis (L.) Nees }\end{array}$ & $36 \pm 18$ & $24 \pm 14$ & $6 \pm 6$ & $18 \pm 18$ \\
$\quad \begin{array}{c}\text { Cyperaceae } \\
\text { Cyperus difformis L. }\end{array}$ & $133 \pm 42$ & $103 \pm 6$ & $91 \pm 38$ & $42 \pm 16$ \\
$\begin{array}{c}\text { Fimbristylis miliacea (L.) Vahl } \\
\text { Scrophulariaceae }\end{array}$ & $867 \pm 105$ & $874 \pm 110$ & $728 \pm 64$ & $904 \pm 98$ \\
$\begin{array}{c}\text { Lindernia procumbens (Krock.) } \\
\text { Philcox }\end{array}$ & $328 \pm 79$ & $419 \pm 46$ & $315 \pm 16$ & $176 \pm 26$ \\
$\begin{array}{c}\text { Lythraceae } \\
\text { Rotala indica (Willd.) Koehne }\end{array}$ & $473 \pm 48$ & $485 \pm 84$ & $388 \pm 68$ & $224 \pm 44$ \\
Amnunnia arenaria Willdenow & 0 & $30 \pm 22$ & $12 \pm 6$ & 0 \\
$\begin{array}{c}\text { Onagraceae } \\
\text { Ludwigia hyssopifolia (G. Don) Exell } \\
\text { Portulacaceae }\end{array}$ & $61 \pm 12$ & $85 \pm 22$ & $24 \pm 6$ & $61 \pm 16$ \\
$\begin{array}{c}\text { Portulaca oleracea L. } \\
\text { Plantaginaceae }\end{array}$ & $91 \pm 18$ & $79 \pm 16$ & $55 \pm 21$ & $36 \pm 18$ \\
Sphenoclea zeylanica Gaertn. & $73 \pm 46$ & $36 \pm 36$ & $36 \pm 21$ & $61 \pm 44$ \\
\hline
\end{tabular}

In both of the early and late seasons of rice growth, the turbid water treatment and rice-duck treatment significantly declined the total soil seed bank density compared with the control and conventional planting treatment (Figure 3). Relative to the control, the rice-duck treatment reduced more than $40 \%$ of soil seed bank density (from $4028 \pm 215$ to $2014 \pm 80$ individuals $\mathrm{m}^{-2}$ in the early season and from $3446 \pm 216$ to $2044 \pm 100$ individuals $\mathrm{m}^{-2}$ in the late season), while the turbid water treatment decreased $18.2 \%$ and $30.5 \%$ of soil seed bank density in the early and late seasons, respectively. There was no significant difference in soil seed bank density between the control and conventional planting treatment (Figure 3). 
Table 2. Soil seed bank composition (individuals $\mathrm{m}^{-2}$ ) under different treatments in the late season of rice growth.

\begin{tabular}{ccccc}
\hline Species & Control & $\begin{array}{c}\text { Conventional } \\
\text { Planting }\end{array}$ & $\begin{array}{c}\text { Turbid Water } \\
\text { Treatment }\end{array}$ & $\begin{array}{c}\text { Rice-Duck } \\
\text { System }\end{array}$ \\
\hline $\begin{array}{c}\text { Gramineae } \\
\text { Alopecurus japonicus Steud. }\end{array}$ & $1335 \pm 119$ & $1583 \pm 155$ & $831 \pm 42$ & $613 \pm 40$ \\
$\begin{array}{c}\text { Echinochloa crusgalli (L.) P. Beauv. } \\
\text { Leptochloa chinensis (L.) Nees } \\
\quad \text { Cyperaceae }\end{array}$ & $146 \pm 18$ & $164 \pm 32$ & $91 \pm 18$ & $127 \pm 11$ \\
$\quad \begin{array}{c}\text { Cyperus difformis L. } \\
\text { Scrophulariaceae }\end{array}$ & $1098 \pm 42$ & $1256 \pm 121$ & $770 \pm 54$ & $655 \pm 111$ \\
$\begin{array}{c}\text { Lindernia procumbens (Krock.) } \\
\text { Philcox }\end{array}$ & $437 \pm 38$ & $473 \pm 46$ & $340 \pm 6$ & $388 \pm 47$ \\
$\begin{array}{c}\text { Lythraceae } \\
\text { Rotala indica (Willd.) Koehne } \\
\text { Ammannia baccifera L. } \\
\text { Onagraceae }\end{array}$ & $42 \pm 6$ & $30 \pm 16$ & $49 \pm 6$ & $18 \pm 11$ \\
$\begin{array}{c}\text { Ludwigia hyssopifolia (G. Don) Exell } \\
\text { Pontederiaceae }\end{array}$ & $42 \pm 16$ & $61 \pm 12$ & $30 \pm 22$ & 0 \\
$\begin{array}{c}\text { Monochoria vaginalis (N. L. } \\
\text { Burman) C. Presl ex Kunth }\end{array}$ & $24 \pm 12$ & $36 \pm 28$ & $24 \pm 6$ & $18 \pm 11$ \\
\hline
\end{tabular}

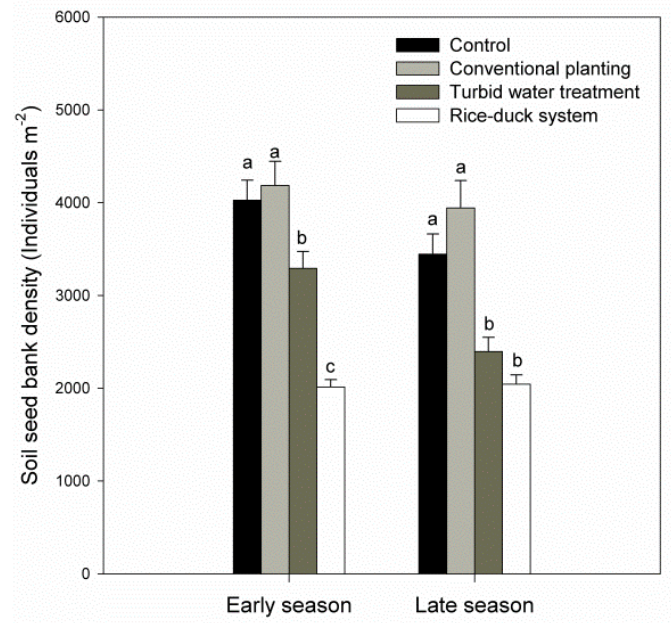

Figure 3. Soil seed bank density in the early and late seasons of rice growth under the treatments and control. Bars present the mean and error bars present the standard error $(n=3)$. Different lowercase letters above bars indicate statistically significant differences among treatments in the early or late rice growing season. Significance level was set at $p<0.05$.

\subsection{Effects on Vertical Distribution of Soil Seed Bank}

Soil seed bank density significantly decreased with increasing soil depth in both the early and late seasons (Figure 4), except in the rice-duck plots. The first surface soil layer (i.e., $0-5 \mathrm{~cm}$ in this study) included on average $>50 \%$ of the investigated soil seed bank in the control, conventional planting, and turbid water plots, while the second soil layer $(5-10 \mathrm{~cm})$ accounted for around $30 \%$, and the third soil layer $(10-15 \mathrm{~cm})$ accounted for the remaining percentage. Compared with the other three treatments, the rice-duck plots presented a quite different pattern that $16.9 \%$ and $26.7 \%$ of seed individuals were detected at the first soil layer in the early and late seasons, respectively, while more than $50 \%$ at the second soil layer and the remaining at the third soil layer. In both the early and late seasons, the second soil layer contributed to most of soil seed bank. 
In each of the three soil layers we investigated, significant differences were detected among the treatments (Figure 4). The turbid water treatment significantly decreased soil seed density by $39.5 \%$ at the first soil layer in the late season relative to the control, while the rice-duck treatment decreased seed density by $83.2 \%$ and $76.3 \%$ in the early and late seasons, respectively. At the second soil layer, the turbid water treatment decreased soil seed density in the two seasons, significantly or not, compared with the control, while the rice-duck farming treatment did not significantly alter (in the early season; Figure 4a) or even increase soil seed density (in late season; Figure 4b). The turbid water treatment significantly declined soil seed density in the early season (Figure 4a). The conventional planting treatment did not significantly change soil seed density in the three soil layers in the early and late seasons, except for the 5-10 cm soil layer in the late season in which there was a significantly higher soil seed density than in the control (Figure 4 b).

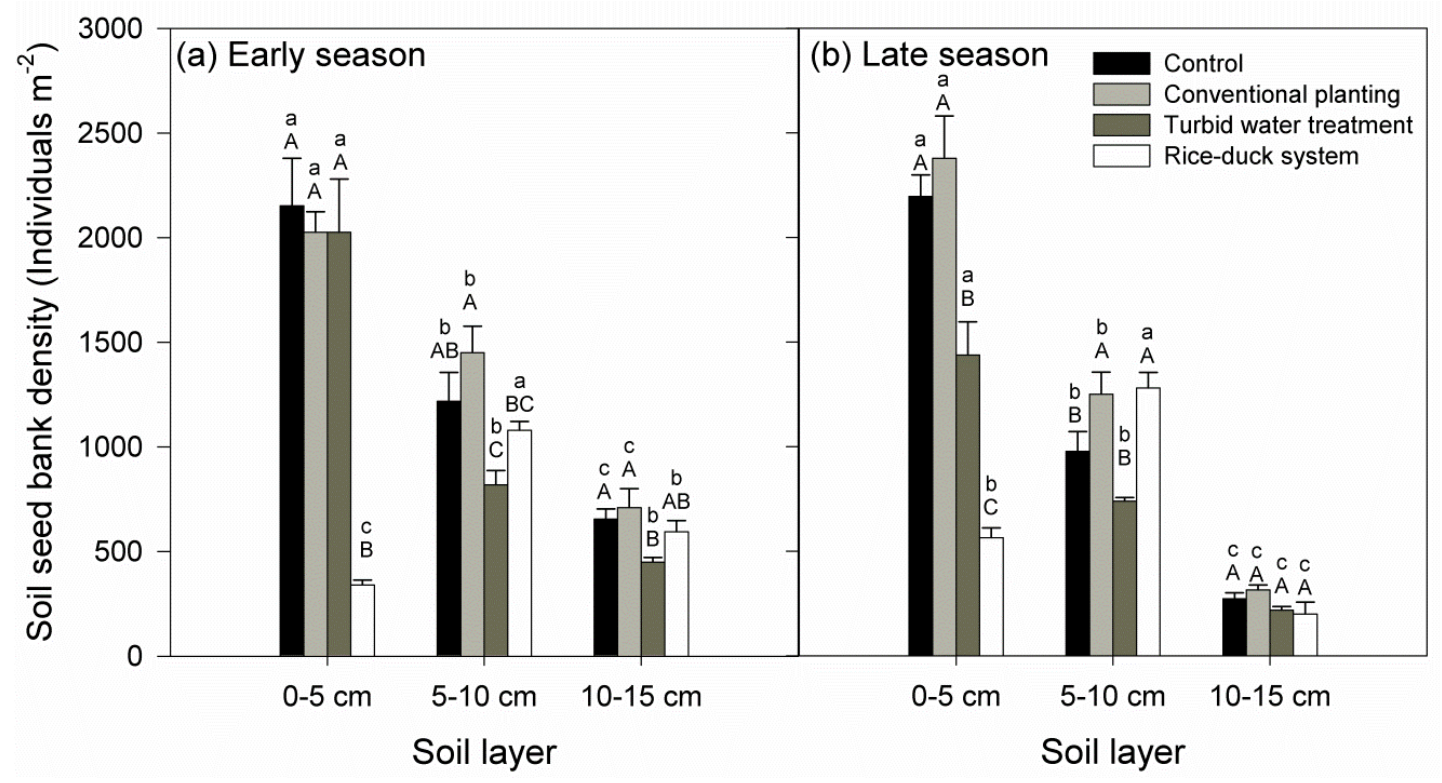

Figure 4. Vertical distribution of soil seed bank in the early (a) and late (b) seasons of rice growth under the treatments and control. Bars present the mean and error bars present the standard error $(n=3)$. Results with the same lowercase letter at the top of the columns are not statistically different among soil depth and with the same capital letter are not statistically different among treatments in each rice season at each soil depth. Significance level was set at $p<0.05$.

\subsection{Effects on Weed Density and Correlations between Weed and Seed Density}

In both the early and late seasons, weed density presented a consistent pattern among the treatments, with the control the greatest, the rice-duck system the fewest and the conventional planting and turbid water treatments in between (Figure 5). Weed density was $43.6 \pm 3.8,40.0 \pm 0.8,28.1 \pm 3.5$, and $2.3 \pm 0.2$ individuals $\mathrm{m}^{-2}$ in the control, conventional planting, turbid water treatment, and rice-duck plots in the early season, respectively, while the figure was $37.5 \pm 2.3,34.3 \pm 1.4,19.1 \pm 1.6$, and $1.1 \pm 0.1$ individuals $\mathrm{m}^{-2}$ accordingly in the late season. Weed density was significantly lower under the rice-duck treatment than under the other three treatments, while it was significantly lower in the turbid water plots than in the control and conventional planting plots in the both seasons. Weed density showed significantly linear relationships with soil seed density in both the early and late seasons and the correlations did not change with season of rice growth (Figure 6a). Weed density in the late season had a significantly positive correlation with soil seed density in the early season (Figure 6b). 


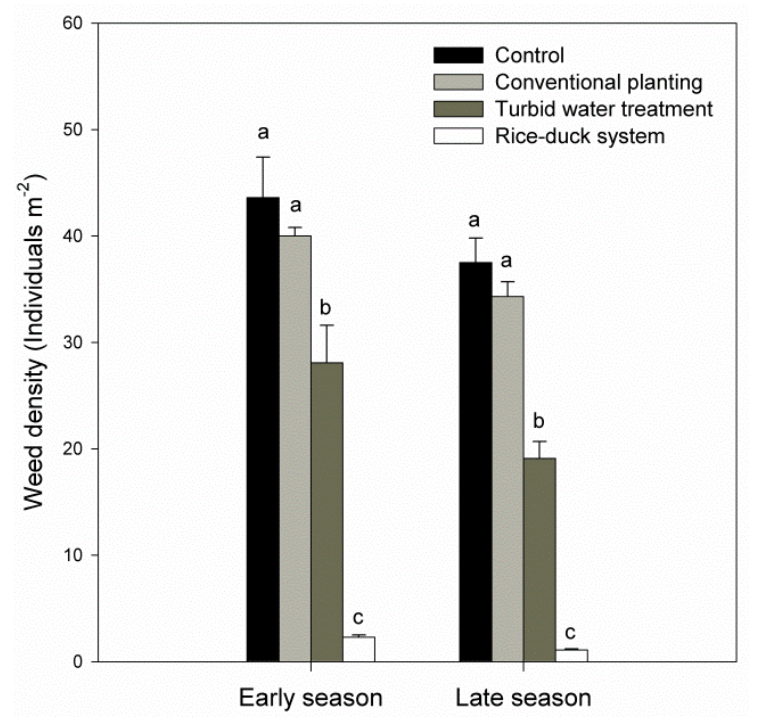

Figure 5. Weed density in the early and late seasons of rice growth under the treatments and control. Bars present the mean and error bars present the standard error $(n=3)$. Different lowercase letters above bars indicate statistically significant differences among treatments in the early or late rice growing season. Significance level was set at $p<0.05$.
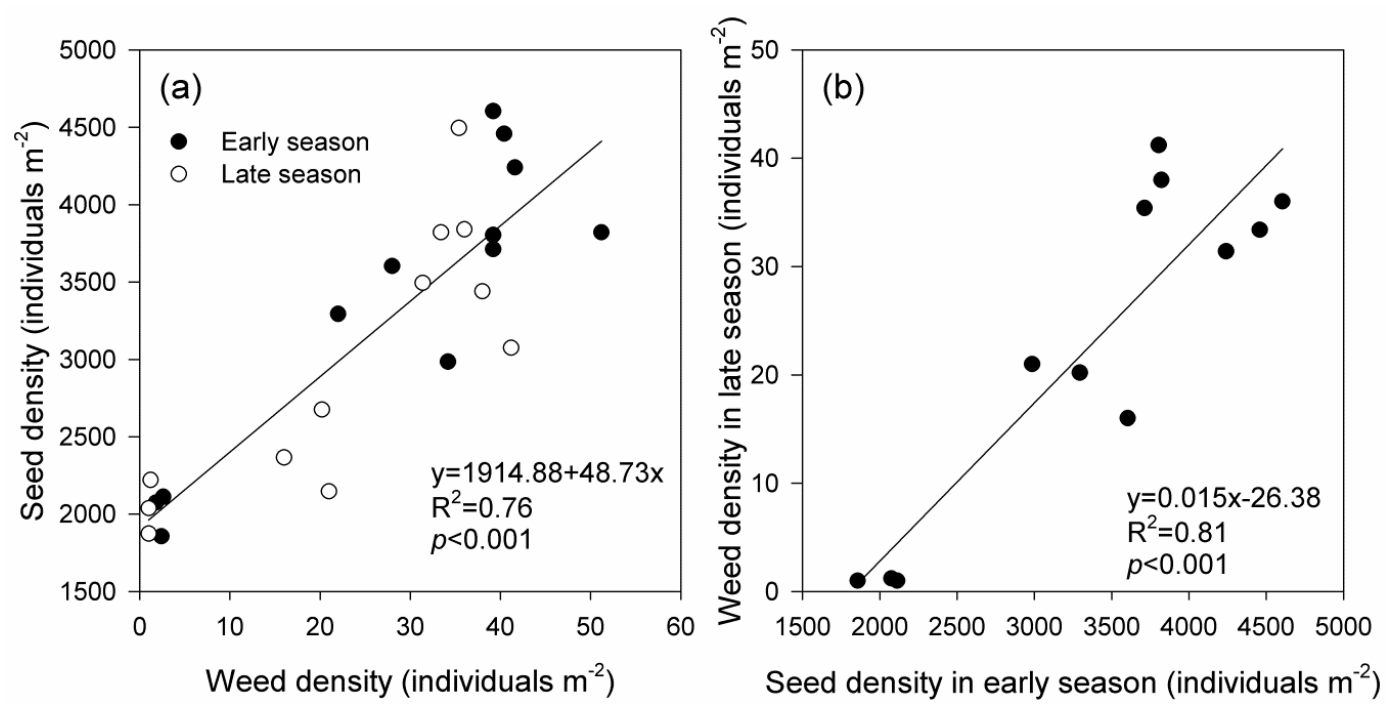

Figure 6. Correlations between soil seed bank density and weed density in the both seasons (a) and between seed density in the early season and weed density in the late season (b). The solid line indicates a significant linear relationship between the two indices in each panel.

\section{Discussion}

Rice-duck farming significantly declined the soil seed bank density in rice paddy fields (Figure 3), supporting the pattern we expected. This is an observation in line with previous studies $[24,30]$ and could be in part attributable to the muddying effect by duck activities. Relative to the control and the conventional planting treatment, the turbid water treatment that represents muddying effect of raising ducks significantly decreased the soil seed bank density (Figure 3), possibly due to turbid water reducing the occurrence of weeds and therefore decreasing the total productivity of seeds. Seed rain is considered to be the most important input of weed seed bank in the soil [24]. Under harsh environmental conditions, weeds trend to reproduce fewer seeds and then relatively lower amount of seed rain than under an undisturbed environmental condition [34]. Previous studies showed that increased turbidity of water decreased the transmission of light and also the light composition [35]. 
The changes in the light environment could also contribute to weed control, because reduced light intensity and altered light composition could probably lower germination of several seeds in the soil $[27,36]$, and the lower weed abundance consequently resulted in the reduction of soil seed bank density. This significant correlation between seed and weed density is also supported by our observation of the significant correlation between the both (Figure 6a).

Besides the muddying effect, duck foraging and trampling significantly contributed to the decline of soil seed bank density in the rice-duck system because the treatment effect was considerably greater in the rice-duck system than in the turbid water treatment (Figure 3). As an omnivorous waterfowl, ducks eat weed seeds, insects, and crabs and move frequently in the fields, thus directly reduced the number of soil seeds [8,24]. Moreover, seeds that were stored in the soil could be stirred up to float on the water by duck activities, consequently making them more vulnerable and unviable [24,30]. This is evidenced by our observation that the rice-duck treatment significantly changed the vertical distribution of soil seed bank and the seed density was significantly decreased in the upper soil layer in the both rice growing seasons (Figure 4). Our results suggest that whilst the muddying effect could only give rise to decline in the soil seed bank density, the rice-duck system (including muddying, trampling, and foraging effects) decreased soil seed bank density to a greater extent and also altered its vertical distribution (Figures 3 and 4). The altered vertical distribution of soil seed bank could affect seed germination rate and then the weed occurrence [24]. However, the rice-duck system did not seem to change the community composition and diversity of soil seed bank because the dominant species and their proportions were comparable among the treatments in both the seasons.

Soil seed bank plays a critical role in the renewal and outbreak of weeds in rice paddy fields because most weeds are annual and the size of weed community depends greatly on the soil seed bank density $[28,29]$. This relationship is well-supported by our observation that soil seed bank density in the early rice growing season was significantly correlated with weed density in the late rice growing season (Figure 6b). Weed damage can be restricted by diverse approaches such as herbicide application and ecological approaches (e.g., planting weed-competitive cultivars and compound planting practices) [37]. Source control, that is to say, decreasing soil seed bank density, is an effective measure to control weeds, since weeds on earth germinate from soil seed bank in the farmland [38,39]. As observed in the present study, lower soil seed bank density could result in significantly lower weed density in the following growing season. Therefore, rice-duck farming is one of the ecological farming techniques and the constant duck movement in the field has an important impact on weed and seed density [13].

Rice-duck farming system has been evidenced as an efficient planting system [8] and could lead to many positive ecological effects, e.g., reducing the warming potential of paddy field [14,15], controlling weed growth [13], and improving soil fertility and soil biodiversity [12], while economic effect can be improved by promoting rice yield and quality in the rice-duck farming $[11,12,40]$. From the aspect of weed control, this system exhibits great advantages over the control and conventional planting system in part due to the declined soil seed bank density and altered its vertical distribution, especially when the rice-duck farming approach was applied continuously in the same paddy fields year by year. This finally lowers the possibility of weed occurrence and then the weed competitions with rice plants, consequently promoting the rice yield [12]. Therefore, the rice-duck farming has been highly recommended to develop in Asia which contributes to $90 \%$ of the total rice production $[8,10]$.

The rice-duck farming system has been studied and practiced for decades and many experiences obtained previously. Increasing biodiversity of crop fields by raising ducks in paddy fields could greatly reduce the needs for agrochemicals while crop productivity is maintained or promoted [12-14]. Previous studies presented that frequency of weed occurrence could be greatly reduced in the rice-duck farming system than in the conventional paddy fields $[12,13]$ and that continuous rice-duck farming could significantly reduce the soil seed bank density [24]. The movements of ducks could affect weed and seed communities by multiple pathways, e.g., foraging and trampling plants and muddying water. They have been rarely considered as separated effects in previous studies. In the present study, we further distinguished the effects of raising ducks in paddy fields into two parts, with the one being 
muddying effect and the other of trampling and foraging effect of ducks in fields. We observed that associated with the movements of ducks in fields, muddying water could greatly reduce the weed occurrence by declining soil seed bank density in surface soils. These results could help further our understanding on the underlying mechanisms by which ways the rice-duck farming system effectively controls the growth of weed community as shown in previous studies [12,13].

\section{Conclusions}

Rice-duck farming had significantly lower soil seed bank density relative to the control and conventional planting system, indicating a considerable effect on weed seed control in the rice-duck farming. Muddying effect by duck activities significantly contributed to the decline in weed seed bank density, likely due to reduced seed germination and growth and then seed production in the turbid water condition. Duck trampling and foraging also had a significant contribution to the declines in soil seed bank and weed density. Our study separated the effects of raising ducks in paddy fields into muddying and foraging/trampling effects. These observations help further our understanding on the underlying mechanisms by which ways the rice-duck farming reduce weed occurrences. It deserves further studies to provide empirical evidences on how the muddying effect could reduce the soil weed density, and it would be interesting to explore whether rice-duck farming could change soil microenvironments that, in turn, affect competition between rice and weed species.

Author Contributions: J.Z. conceived and designed the experiment; R.C. and G.Q. conducted the investigations; H.W., W.B. and H.X. analyzed the data and wrote the draft; all the authors contributed to result explanations and manuscript revisions.

Funding: This research was funded by the National Basic Research Program of China, grant number 2006CB100206 and 2011CB100406; the Science and Technology Project of Guangdong Province, grant number 2015B090903077 and 2016A020210094; the Science and Technology Project of Guangzhou, grant number 201604020062; and the Innovation Team Construction Project of Modern Agricultural Industry Technology System of Guangdong Province, grant number 2016LM1100 and 2018LM1100.

Acknowledgments: We appreciate An M (Clarles Sturt University, Australia) for his evaluable comments on our early draft.

Conflicts of Interest: The authors declare no conflict of interest.

\section{References}

1. Sun, F.; Dai, Y.; Yu, X. Air pollution, food production and food security: A review from the perspective of food system. J. Integr. Agric. 2017, 16, 60345-60347. [CrossRef]

2. Melts, I.; Lanno, K.; Sammul, M.; Uchida, K.; Heinsoo, K.; Kull, T.; Laanisto, L.; Niu, K. Fertilising semi-natural grasslands may cause long-term negative effects on both biodiversity and ecosystem stability. J. Appl. Ecol. 2018, 55, 1951-1955. [CrossRef]

3. Barmentlo, S.H.; Schrama, M.; Hunting, E.R.; Heutink, R.; van Bodegom, P.M.; de Snoo, G.R.; Vijver, M.G. Assessing combined impacts of agrochemicals: Aquatic macroinvertebrate population responses in outdoor mesocosms. Sci. Total Environ. 2018, 631, 341-347. [CrossRef] [PubMed]

4. Guo, X.; Li, H.; Yu, H.; Li, W.; Ye, Y.; Biswas, A. Drivers of spatio-temporal changes in paddy soil pH in Jiangxi Province, China from 1980 to 2010. Sci. Rep. 2018, 8, 2702. [CrossRef]

5. Carvalho, F.P. Agriculture, pesticides, food security and food safety. Environ. Sci. Policy 2006, 9, 685-692. [CrossRef]

6. Carvalho, F.P. Pesticides, environment, and food safety. Food Energy Secur. 2017, 6, 48-60. [CrossRef]

7. Zhang, J.E.; Ouyang, Y.; Huang, Z.X. Characterization of nitrous oxide emission from a rice-duck farming system in South China. Arch. Environ. Contam. Toxicol. 2008, 54, 167-172. [CrossRef]

8. Pernollet, C.A.; Simpson, D.; Gauthier-Clerc, M.; Guillemain, M. Rice and duck, a good combination? Identifying the incentives and triggers for joint rice farming and wild duck conservation. Agric. Ecosyst. Environ. 2015, 214, 118-132. [CrossRef]

9. Mueller, M.H.; van der Valk, A.G. The potential role of ducks in wetland seed dispersal. Wetlands 2002, 22, 170-178. [CrossRef] 
10. Suh, J. Theory and reality of integrated rice-duck farming in Asian developing countries: A systematic review and SWOT analysis. Agric. Syst. 2014, 125, 74-81. [CrossRef]

11. Li, M.; Zhou, N.; Zhang, J.; Xiang, H.; Liang, K. Effect of rice varieties mixed-cropping with duck raising on nutrient dynamics in paddy soils. Chin. J. Eco-Agric. 2017, 25, 211-220. [CrossRef]

12. Teng, Q.; Hu, X.-F.; Cheng, C.; Luo, Z.; Luo, F.; Xue, Y.; Jiang, Y.; Mu, Z.; Liu, L.; Yang, M. Ecological effects of rice-duck integrated farming on soil fertility and weed and pest control. J. Soil Sediments 2016, 16, 2395-2407. [CrossRef]

13. Zhang, J.E.; Xu, R.B.; Chen, X.; Quan, G.M. Effects of duck activities on a weed community under a transplanted rice-duck farming system in southern China. Weed Biol. Manag. 2009, 9, 250-257. [CrossRef]

14. Xu, G.; Liu, X.; Wang, Q.; Yu, X.; Hang, Y. Integrated rice-duck farming mitigates the global warming potential in rice season. Sci. Total Environ. 2017, 575, 58-66. [CrossRef] [PubMed]

15. Zhan, M.; Cao, C.; Wang, J.; Jiang, Y.; Cai, M.; Yue, L.; Shahrear, A. Dynamics of methane emission, active soil organic carbon and their relationships in wetland integrated rice-duck systems in Southern China. Nutr. Cycl. Agroecosyst. 2010, 89, 1-13. [CrossRef]

16. Zhao, B.; Wen, T.; Zhang, J.; Tang, W.; Wang, M. Duck trampling in rice-duck farming alters rice growth and soil $\mathrm{CH}_{4}$ emissions. Int. J. Agric. Biol. 2019, 21, 345-350. [CrossRef]

17. Liang, K.; Zhang, J.; Song, C.; Luo, M.; Zhao, B.; Quan, G.; An, M. Integrated Management to Control Golden Apple Snails (Pomacea canaliculata) in Direct Seeding Rice Fields: An Approach Combining Water Management and Rice-Duck Farming. Agroecol. Sustain. Food Syst. 2014, 38, 264-282. [CrossRef]

18. Huang, S.; Wang, L.; Liu, L.; Fu, Q.; Zhu, D. Nonchemical pest control in China rice: A review. Agron. Sustain. Dev. 2013, 34, 275-291. [CrossRef]

19. Zhang, J.; Lu, J.; Zhang, G.; Luo, S. Study on the function and benefit of rice-duck agroecosystem. Ecol. Sci. 2002, 21, 6-10.

20. Wang, Q.; Huang, P.; Zhen, R.; Jing, L.; Tang, H.; Zhang, C. Effect of rice-duck mutualism on nutrition ecology of paddy field and rice quality. Chin. J. Appl. Ecol. 2004, 15, 639-645. [CrossRef]

21. Yu, S.; Ouyang, Y.; Zhang, Q.; Peng, G.; Xu, D.; Jin, Q. Effects of rice-duck farming system on oryza sativa growth and its yield. Chin. J. Appl. Ecol. 2005, 16, 1252-1256. [CrossRef]

22. Wang, H.; Huang, H.; Yang, Z.; Liao, X. Integrated benefits of paddy rice-duck complex ecosystem. Rural Eco-Environ. 2003, 19, 23-26.

23. Wei, S.; Qiang, S.; Ma, B.; Wei, J.; Chen, J.; Wu, J.; Xie, T.; Shen, X. Control effects of rice-duck farming and other weed management strategies on weed communities in paddy fields. Chin. J. Appl. Ecol. 2005, 16, 1067-1071. [CrossRef]

24. Li, S.-S.; Wei, S.-H.; Zuo, R.-L.; Wei, J.-G.; Qiang, S. Changes in the weed seed bank over 9 consecutive years of rice-duck farming. Crop Prot. 2012, 37, 42-50. [CrossRef]

25. Liu, X.; Yang, Z.; Huang, H.; Hu, L.; Chen, Y.; Wen, Z. Developing rules of field weeds in wetland rice-duck compounded system. J. Hunan Agric. Univ. (Nat. Sci.) 2004, 30, 292-294. [CrossRef]

26. Yu, S.; Jin, Q.; Ouyang, Y.; Xu, D. Efficiency of controlling weeds, insect pests and diseases by raising ducks in the paddy fields. Chin. J. Biol. Control 2004, 20, 99-102. [CrossRef]

27. Wei, S.; Qiang, S.; Ma, B.; Wei, J.; Chen, J.; Wu, J.; Xie, T.; Shen, X. Influence of long-term rice-duck farming systems on the composition and diversity of weed communities in paddy fields. J. Plant Ecol. 2006, 30, 9-16. [CrossRef]

28. Cavers, P.B.; Benoit, D.L. CHAPTER 14-Seed Banks in Arable Land. In Ecology of Soil Seed Banks; Parker, V.T., Simpson, R.L., Eds.; Academic Press: Cambridge, MA, USA, 1989; pp. 309-328. [CrossRef]

29. Mesquita, M.L.R. Weed Seedbank in Rice Fields. In Advances in Interanational Rice Research; Li, J., Ed.; InTechOpen: London, UK, 2017. [CrossRef]

30. Zhao, C.; Dai, W.; Li, S.; Wei, S.; Wei, J.; Zhang, C.; Qiang, S. Change in weed seed bank diversity over 13 consecutive years of rice-duck and straw returning farming system in the rice-wheat rotated wheat fields. Biodivers. Sci. 2014, 22, 366-374. [CrossRef]

31. Liu, Z.; Li, Z.; Tang, P.; Li, Z.; Wu, W.; Yang, P.; You, L.; Tang, H. Spatial-temporal changes of rice area and production in China during 1980-2010. Acta Geogr. Sin. 2013, 68, 680-693.

32. Monthly Average Air Temperature and the Amount of Precipitation in Guangzhou in Year 2006. Available online: https://rp5.ru (accessed on 13 May 2019). 
33. Tang, H. Illustrated Handbook of Farmland Weeds in China; Shanghai Scientific \& Technical Publishers: Shanghai, China, 1989.

34. Bello, I.A.; Owen, M.D.K.; Hatterman-Valenti, H.M. Effect of Shade on Velvetleaf (Abutilon theophrasti) Growth, Seed Production, and Dormancy. Weed Technol. 1995, 9, 452-455. [CrossRef]

35. Gray, S.M.; Sabbah, S.; Hawryshyn, C.W. Experimentally increased turbidity causes behavioural shifts in Lake Malawi cichlids. Ecol. Freshw. Fish 2011, 20, 529-536. [CrossRef]

36. Kruk, B.; Insausti, P.; Razul, A.; Benech-Arnold, R. Light and thermal environments as modified by a wheat crop: Effects on weed seed germination. J. Appl. Ecol. 2006, 43, 227-236. [CrossRef]

37. Dass, A.; Shekhawat, K.; Choudhary, A.K.; Sepat, S.; Rathore, S.S.; Mahajan, G.; Chauhan, B.S. Weed management in rice using crop competition-A review. Crop Prot. 2017, 95, 45-52. [CrossRef]

38. Wang, H.; Han, X. The actuality and expectation of weeds sustainable management in China. J. Shanxi Agric. Univ. (Nat. Sci. Ed.) 2002, 3, 274-277. [CrossRef]

39. Qiang, S.; Shen, J.; Zhang, C.; Shao, G.; Hu, J.; Wang, F. The influence of cropping systems on weed communities in the cotton fields of Jiangsu Province. Acta Phytoecol. Sin. 2003, 27, 278-282.

40. Liu, X.; Xu, G.; Wang, Q.; Hang, Y. Effects of Insect-Proof Net Cultivation, Rice-Duck Farming, and Organic Matter Return on Rice Dry Matter Accumulation and Nitrogen Utilization. Front. Plant Sci. 2017, 8, 47. [CrossRef] [PubMed]

(C) 2019 by the authors. Licensee MDPI, Basel, Switzerland. This article is an open access article distributed under the terms and conditions of the Creative Commons Attribution (CC BY) license (http://creativecommons.org/licenses/by/4.0/). 